\title{
Effects of lung volume reduction surgery in hamsters with elastase-induced emphysema
}

\author{
E. Marchand*,ף, P. De Leyn*, G. Gayan-Ramirez*, F. Palecek*, E. Verbeken ${ }^{+}$, M. Decramer*
}

Effects of lung volume reduction surgery in hamsters with elastase-induced emphysema. E. Marchand, P. De Leyn, G. Gayan-Ramirez, F. Palecek, E. Verbeken, M. Decramer. (C) ERS Journals Ltd 2002.

ABSTRACT: Lung volume reduction surgery (LVRS) has been shown to improve respiratory mechanics in selected patients with severe emphysema. This is thought to be due to an improvement in lung elastic recoil. This study was aimed at gaining further understanding about the effects of LVRS on respiratory mechanics and airway function.

Control hamsters instilled with saline $(\mathrm{Ctrl} ; \mathrm{n}=8)$ were compared with emphysematous animals that underwent either a sham operation (Sham; $n=7$ ) or an LVRS (LVRS; $\mathrm{n}=7$ ).

As expected, there was a significant increase in the static lung volumes in the Sham as compared to the Ctrl group and a significant decrease of these volumes in LVRS as compared to the Sham group. Surprisingly, emphysema was associated with a significant increase and LVRS with a significant decrease in vital capacity. Despite a tendency toward an increase in lung compliance as compared to Sham, indices of maximal expiratory flows tended to decrease with LVRS. As opposed to humans, there was no change in the distribution of airway diameters in Sham compared to Ctrl.

These findings appear to be largely explained by the high compliance of the hamster chest wall. This allows for better matching between the emphysematous lung and the chest-wall sizes than in humans.

Eur Respir J 2002; 19: 422-428.
*Respiratory Muscle Research Unit, Laboratory of Pneumology, ${ }^{\text {Dept of }}$ Thoracic Surgery, "Dept of Histopathology, University Hospitals, Katholieke Universiteit Leuven, Leuven and ${ }^{+}$Dept of Pneumology, Mont-Godinne Université Catholique de Louvain University Hospital, Yvoir, Belgium.

Correspondence: M. Decramer, Respiratory Muscle Research Unit, Laboratory of Pneumology, University Hospitals, Katholieke Universiteit Leuven, B-3000 Leuven, Belgium.

Fax: 3216347126

E-mail: marc.decramer@uz.kuleuven. ac.be

Keywords: Airway obstruction, emphysema, maximal expiratory flow rate, pneumonectomy, respiratory mechanics

Received: September 62001

Accepted after revision November 22 2001

This study was supported by FWOVlaanderen grant G.0175.99 and KULeuven Research Foundation grant OT98/27. G. Gayan-Ramirez is postdoctoral fellow of the FWO-Vlaanderen.
Lung volume reduction surgery (LVRS) has been shown to have a beneficial effect on lung function, submaximal exercise capacity and quality of life in selected patients with severe emphysema [1-3], although individual results classically demonstrate large scatter [1]. Initially, it was proposed that the increase in maximal expiratory flow (MEF) observed after LVRS was mainly due to an improvement in lung elastic recoil after the surgical procedure [4]. Although attractive, this hypothesis does not completely explain the increase in MEF in every patient [4], nor does it explain the increase in vital capacity (VC) generally observed after LVRS [5]. Recently, Fessler and Permutt [5] proposed a mathematical model whereby they demonstrated that other factors were critical for the improvements in lung function after LVRS. According to their model, they predicted that the mismatch between the lung and the chest-wall dimensions were the most important determinants of airflow limitation in patients with severe emphysema. Hence, the effects of LVRS on airway function would be largely due to improvement of that match.
Interestingly, pathological studies have provided evidence that a competition for space between emphysematous zones and airways could occur in emphysematous lungs. Using three-dimensional reconstructions of the small airways and septal system, VERBEKEN et al. [6] suggested that as well as intrinsic airway narrowing due to inflammation and loss of elastic lung recoil, the competition for space could also cause flow limitation. The aforementioned mismatch between lung and chest-wall volumes could also play an important role in these pathological findings.

In an attempt to better understand the determinants of improvement in respiratory mechanics following LVRS, the effects of LVRS on respiratory mechanics, airway function and morphometry were assessed in a model of elastase-induced emphysema in hamsters. In contrast to humans, hamsters have a highly compliant chest wall. Accordingly, the mismatch between lung and chest-wall dimensions and the competition for space within the lung would be less marked than in emphysematous humans. Following the model of Fessler and Permutt [5] this would lead to a less 
marked or even no improvement in airway function after LVRS.

\section{Materials and methods}

\section{Study animals}

Male 9-week-old Syrian golden hamsters were purchased. One week after purchase, the animals were anaesthetized with sodium pentobarbital (Nembutal, Sanofi Santé Animale Benelux, Brussels, Belgium; $60 \mathrm{mg} \cdot \mathrm{kg}^{-1}$ body weight (bw) i.p.) and underwent transoral tracheal intubation with a 16GA catheter (Insyte-W catheter, Becton Dickinson, Madrid, Spain). Hamsters were instilled on a random basis with either porcine pancreatic elastase (Sigma $40 \mathrm{U} \cdot 100 \mathrm{~g} \mathrm{bw}^{-1}$ and sodium chloride $(0.9 \%)$ added to a total volume of $0.4 \mathrm{~mL}, \mathrm{n}=20)$ or $0.4 \mathrm{~mL}$ sodium chloride $(0.9 \%)$ $(\mathrm{n}=8$, control $(\mathrm{Ctrl}))$. One of the animals instilled with elastase died soon after extubation due to tracheal perforation. Eight animals were kept in each cage and provided with standard laboratory chow and water at will. They were the same as those studied in a previous paper on the effects of LVRS on the diaphragm [7]. All experiments received the approval of the animal experiments committee of the Medical Faculty of the Katholieke Universiteit Leuven.

\section{Study design}

Eighteen weeks after intratracheal-elastase instillation, the animals instilled with elastase randomly underwent either LVRS $(n=11)$ or a Sham operation $(n=8)$. More animals were allocated to LVRS because of the expected mortality. Nine weeks after surgery or at an equivalent time for the eight Ctrl animals, experimental procedures were performed, including static lung-volume measurements, respiratory mechanics assessment, and MEF measurements. Thereafter, the lungs were removed en bloc and were fixated for further airway morphometric analysis. The variables were compared across the three groups in order to assess the effect of emphysema and LVRS.

\section{Surgical procedure}

The surgical procedure has been reported in detail previously [7]. Briefly, it consisted of a sternotomy and a bilateral lung resection aimed at removing 25-30\% of the volume, as estimated visually. In practice, this was generally obtained by resection of most of the right cranial and left upper lobes as well as the anterior part of the right middle and left lower lobes, according to the description by PATRA [8] of the hamster's bronchial anatomy. The animals of the Sham group underwent the same procedure except for the lung resection. Once the animals resumed spontaneous ventilation they were extubated and placed in an atmosphere enriched in oxygen for a few hours.

Three hamsters of the LVRS group died soon after the end of the surgical procedure. Autopsy revealed a significant amount of blood in one of the pleural cavities in the three cases. A fourth animal of the LVRS group died on the fifth operative day in a comatose state. Air leakage was never a problem.

\section{Lung volume measurements}

Nine weeks after the surgical procedure (and at equivalent age for the Ctrl animals), the animals were anaesthetized with a mixture of sodium pentobarbital (3 mg $\left.\cdot 100 \mathrm{~g} \mathrm{bw}^{-1}\right), \alpha$-chloralose $\left(3.8 \mathrm{mg} \cdot 100 \mathrm{~g} \mathrm{bw}^{-1}\right)$, and urethane $\left(38 \mathrm{mg} \cdot 100 \mathrm{~g} \mathrm{bw}^{-1}\right)$, as modified from REID et al. [9]. They were tracheostomized and the trachea was cannulated with a 16GA catheter from which the narrowed tip was removed. Measurements of functional residual capacity (FRC) and total lung capacity (TLC25), residual volume (RV-20), and VC were performed using a setting modified from Koo et al. [10]. Accordingly, TLC25 and RV-20 were defined as the lung volumes at a transpulmonary pressure $(P \mathrm{~L})$ equal to $25 \mathrm{cmH}_{2} \mathrm{O}$ and $-20 \mathrm{cmH}_{2} \mathrm{O}$, respectively. Rather than using a constant volume plethysmograph, a flow plethysmograph, as described by PALECEK et al. [11], was used. Accordingly, a pneumotachograph (Hans Rudolph 8420B; Hans Rudolph Inc., Kansas City, MO, USA), connected to a differential pressure transducer (MP45, Validyne, Northbridge, CA, USA; range $\pm 2 \mathrm{cmH}_{2} \mathrm{O}$ ), was placed in the wall of a body box and volume changes were calculated by integration of the flow signal. Measurements of elastic properties were performed by analysing the expiratory limb of the quasistatic pressure/volume curve from TLC25 to RV-20. The slope of the best-fit regression line between $P \mathrm{~L}$ (mouth pressure ( $P$ mouth)-oesophageal pressure $\left.\left(P_{\text {oes }}\right)\right)$ and lung volume was defined as lung compliance $(\mathrm{CL})$, and that between pressure across the respiratory system ( $P$ mouth) and lung volume as respiratory-system compliance (CRS).

The forced expirations were performed using chest compression. For this purpose, the body plethysmograph was used as an airtight box in order to induce negative pressure (and inspiration) and positive pressure (expiration). The animals were hyperventilated in order to induce apnoea. Negative pressure was then applied to the body box with a large syringe airtight-connected to the body box. Once a pressure of $-30 \mathrm{cmH}_{2} \mathrm{O}$ was reached, air was abruptly pumped in the body box to induce a pressure $>30 \mathrm{cmH}_{2} \mathrm{O}$. Volume changes applied to the syringe were standardized in order to achieve reproducibility in pressure changes in the body box. Flow was measured at the airway opening during the forced expiratory manoeuvre. The following indices were used to analyse forced expiration: the time needed to exhale $75 \%$ of the forced vital capacity (FVC), defined as the difference between maximal lung volume before the forced expiration and minimal volume at the end of expiration; forced expiratory volume in $100 \mathrm{~ms}$ (FEV0.1); and maximal mid-expiratory flow (MMEF), defined as the mean maximal expiratory flow between $25-75 \%$ of FVC. All measurements were performed at least in triplicate in order to achieve three reproducible measurements. These were averaged for statistical analysis. 


\section{Airway morphometry}

After lung function testing, the animals received an overdose of pentobarbital and the heart-lung block was removed while the animal was mechanically ventilated. The trachea was sectioned above the tracheostomy and the lungs were perfused intratracheally for $72 \mathrm{~h}$ with a $30 \%$ formalin solution at a pressure of $25 \mathrm{cmH}_{2} \mathrm{O}$. Paraffin midsagittal (4 $\mu \mathrm{m}$ sections) from both lungs were stained with haematoxylin-eosin. The stained slices were examined by light microscopy (magnification $\times 20$ ). The microscope was connected to a computerized image analysis system (Quantimet 500; Leica, Cambridge Ltd, UK). The dimensions of all noncartilaginous airways were measured. The airway diameter was measured from basement membrane to basement membrane. The lesser diameters were measured in obliquely sectioned airways [12] (fig. 1). Only small airways (diameter (d) $<500$ microns) were taken into account.

\section{Statistical analysis}

The three groups were compared using a oneway analysis of variance (ANOVA) test and a

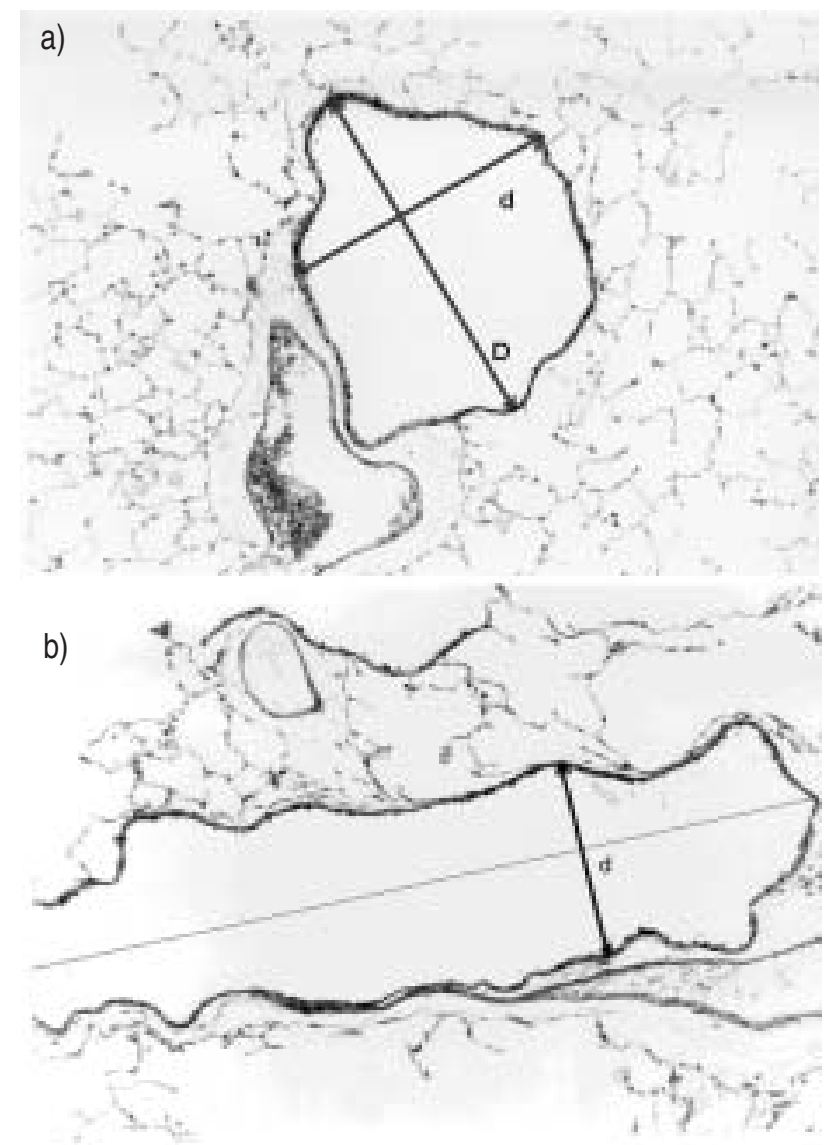

Fig. 1.-Measurement of airway diameters. a) Measurement of the diameter (d) in transversally sectioned airways: the lesser diameter (i.e. the greatest distance between airway walls in an axis perpendicular to the greatest diameter (D)) was measured. b) Measurement of $\mathrm{d}$ in longitudinally sectioned airways: the $\mathrm{D}$ perpendicular to the airway axis (thin line) was measured.
Newman-Keuls multiple comparison post-test for data with a Gaussian distribution. A Kruskal-Wallis test with a Dunn's multiple comparison post-test was used for data without a Gaussian distribution. The distribution of airway diameters was analysed using a Kolmogorov-Smirnov test. The significance level $(\alpha)$ was set at 0.05 .

\section{Results}

\section{Lung volumes}

As previously reported [7], both FRC and TLC25 differed significantly between groups. As can be seen from table 1, emphysema was associated with a large increase in FRC and LVRS, with a 25-30\% decrease as compared to Sham. Similar changes were observed for TLC25, although with a smaller magnitude. The development of emphysema was associated with a significant increase in VC, which was partially but significantly reversed by LVRS. As for FRC, a large change in RV-20 in emphysema associated with a three-fold increase was observed. Because of a proportionally smaller increase in $\mathrm{RV}-20$, the changes in the ratio $\mathrm{RV}-20 / \mathrm{TLC} 25$ were less dramatic.

\section{Lung compliance}

As expected, CL was highly increased in Sham as compared to Ctrl. Although not reaching statistical significance $(\mathrm{p}=0.09)$, there was a tendency for a decrease in CL after LVRS. The same pattern of changes was observed for CRS. Because of a smaller standard error, however, differences were significant between Sham and LVRS (table 2).

\section{Expiratory flows}

As shown in figure 2, emphysema was associated with a characteristic obstructive pattern of the

Table 1.-Static lung volumes

\begin{tabular}{lrccc}
\hline & Ctrl & Sham & LVRS & p-value \\
\hline FRC mL & $1.4 \pm 0.1$ & $4.1 \pm 0.5^{* * *}$ & $3.1 \pm 0.2^{* *}$, & $<0.0001$ \\
TLC25 mL & $7.5 \pm 0.2$ & $13.2 \pm 0.8^{* * *}$ & $10.7 \pm 0.5^{* * *, \#}$ & $<0.0001$ \\
VC mL & $6.5 \pm 0.1$ & $9.7 \pm 0.4^{* * *}$ & $8.4 \pm 0.4^{* * *,}$ & $<0.0001$ \\
RV-20 mL & $1 \pm 0.1$ & $3.5 \pm 0.7^{* * *}$ & $2.3 \pm 0.1^{*}$, & $<0.001$ \\
RV-20/ & $13 \pm 1.7$ & $26 \pm 3.3^{* *}$ & $22 \pm 1.1^{* *}$ & 0.001 \\
TLC25\% & & & & \\
\hline
\end{tabular}

Data are presented as mean \pm SEM. LVRS: lung volume reduction surgery; FRC: functional residual capacity; TLC25: total lung capacity at a transpulmonary pressure equal to $25 \mathrm{cmH}_{2} \mathrm{O}$; VC: vital capacity; $\mathrm{RV}-20$ : residual volume at a transpulmonary pressure equal to $-20 \mathrm{cmH}_{2} \mathrm{O}$. $\mathrm{p}$-Values significantly different from control (Ctrl). ***: $\mathrm{p}<0.001 ;{ }^{* *}: \mathrm{p}<0.01 ; *: \mathrm{p}<0.05 ; \mathrm{p}$-values significantly different from Sham; ${ }^{\#}: \mathrm{p}<0.01 ;{ }^{\uparrow}: \mathrm{p}<0.05 ;{ }^{+}$: as determined by analysis of variance. 
Table 2. - Respiratory mechanics and maximal expiratory flow indices

\begin{tabular}{lcccc}
\hline & Ctrl & Sham & LVRS & p-value $^{+}$ \\
\hline $\mathrm{CL} \mathrm{mL} \cdot \mathrm{cmH}_{2} \mathrm{O}^{-1}$ & $0.9 \pm 0.07$ & $3.4 \pm 1.06^{* *}$ & $2.4 \pm 0.64^{*}$ & $<0.001$ \\
$\mathrm{CRS} \mathrm{mL} \cdot \mathrm{cmH}_{2} \mathrm{O}^{-1}$ & $0.62 \pm 0.02$ & $1.32 \pm 0.14^{* * *}$ & $0.9 \pm 0.07^{* *}, \#$ & $<0.0001$ \\
Time to $75 \% \mathrm{FVC} \mathrm{s}^{*}$ & $0.14 \pm 0.01$ & $0.36 \pm 0.07^{* *}$ & $0.44 \pm 0.07^{* *}$ & $<0.005$ \\
FEV $0.1 \mathrm{~mL}$ & $3.4 \pm 0.19$ & $2.8 \pm 0.2^{*}$ & $2.3 \pm 0.2^{* *}$ & $<0.005$ \\
MMEF $\mathrm{mL} \cdot \mathrm{s}^{-1}$ & $44.9 \pm 2.61$ & $17.8 \pm 3.21^{* * *}$ & $13.3 \pm 3.15^{* * *}$ & $<0.0001$ \\
\hline
\end{tabular}

Data are presented as mean \pm SEM. LVRS: lung volume reduction surgery; $C_{L}$ : lung complicance; CRS: respiratory system compliance; FVC: forced vital capacity; FEV0.1: forced expiratory volume in $100 \mathrm{~ms}$; MMEF: maximal mid-expiratory flow. p-Values significantly different from control (Ctrl). ${ }^{* *}: \mathrm{p}<0.001 ; * *: \mathrm{p}<0.01 ;{ }^{*}: \mathrm{p}<0.05$; $^{\#}$ : significantly different from Sham at $\mathrm{p}<0.01{ }^{+}$: as determined by analysis of variance.

MEF/volume curve. This translated to a clear-cut increase in time to expel $75 \% \mathrm{FVC}$, and decrease in FEV0.1 and MMEF. Despite the increase in elastance observed after LVRS, no beneficial effect of LVRS in terms of MEF indices was observed. There were no significant differences in these indices between Sham and LVRS. Despite a tendency toward a decrease in $\mathrm{CL}$ and, hence, an increased lung elastic recoil, LVRS was associated with a reduction in MEF indices.

\section{Airway morphometry}

Figure 3 depicts the repartition of airway diameters in the three groups. As can be seen from the moving average line, there was not much difference in the proportion of airways with a diameter $>250 \mu \mathrm{m}$ between Sham and Ctrl. In airways with a diameter $<250 \mu \mathrm{m}$, however, a small shift from higher to smaller diameters in Sham and LVRS as compared to Ctrl was observed. In LVRS as compared to Sham, a flatter repartition was observed, with a relatively higher proportion of airways with a diameter $>250 \mu \mathrm{m}$. However, the analysis of the distribution of diameter between Ctrl and Sham and between Sham and LVRS (Kolmogorov-Smirnov test) did not reveal any significant difference.

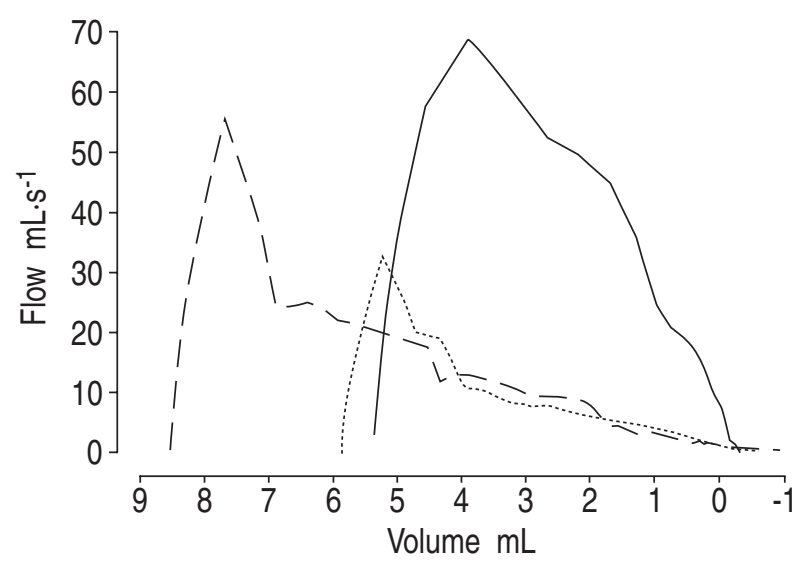

Fig. 2.-Maximal expiratory flow/volume curves. Representative maximal expiratory flow/volume curves from animals of control $(-)$, Sham $(---)$ and lung volume reduction surgery $(\cdots \cdots \cdots . .$. groups are depicted. For convenience, functional residual capacity was arbitrarily set as the point of 0 volume.

\section{Discussion}

The present study allowed several important observations to be made. First, LVRS had no beneficial effects on MEF in hamsters with elastaseinduced emphysema. Secondly, elastase-induced emphysema in hamsters was associated with changes in static lung volumes that were strikingly different from those found in human emphysema. Thirdly, the changes in airway morphometry observed in the present study were also less marked than in human emphysema. All these observations point to important distinctions between respiratory system mechanics of emphysematous humans and hamsters. Its hypothesized that the difference in chest-wall compliance $(\mathrm{CW})$ is the main determinant for the dissimilarities between humans and hamsters.

An important difference between emphysema in hamsters and humans is the smaller effect of LVRS on MEF and the lack of positive effect of LVRS in hamsters. LVRS in emphysematous hamsters was associated with a reduction of expiratory flow limitation. The model of FESSLER and PERMUTT [5] predicts that the per cent increase in FEV1 would be directly related to the RV/TLC ratio and inversely related to the slope of the pressure/volume curve of the chest wall under conditions of maximal inspiratory muscle activity $(\mathrm{CWmax}) / \mathrm{CL}$.

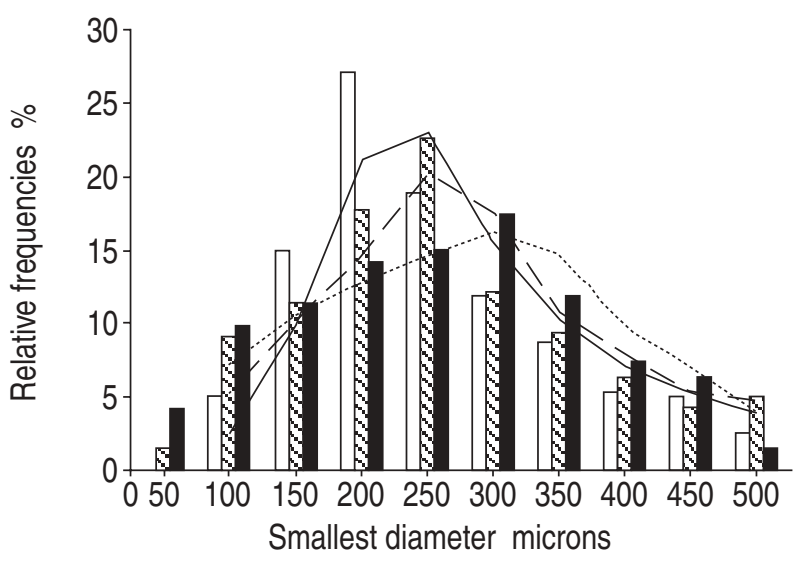

Fig. 3.- Mean frequency distribution of peripheral airways. Histogram of the repartition of airway diameters and moving average line in the control $(\square,-)$, Sham $(\mathbb{\mathbb { N } ,},--)$, and lung volume reduction surgery $(\mathbf{\square}, \cdots \cdots \cdots \cdot)$ groups. 
The mean RV/TLC ratio in Sham was 26\%. This compares to values of $\sim 65 \%$ in patients selected for LVRS in a large series in the literature $[13,14]$. It could be argued that the low RV/TLC ratio in the present study is caused by the definition of RV and TLC in hamsters. Nevertheless, as in humans, RV is determined by the closing volume, as can be seen from figure 4. Regarding TLC25, however, its definition could lead to an artificial overestimation as compared to "voluntary TLC". Indeed, the detrimental effects of hyperinflation on inspiratory-muscle efficiency lead to the inability to develop a transpulmonary pressure in emphysematous subjects as high as that in normal subjects [15]. However, if TLC increased by a $20 \%$ margin as is observed in patients, the RV/TLC would still only approach $39 \%$, which remains very low. Moreover, given the shape of the lung pressure/ volume curve (fig. 4), even a dramatic decrease in the force or mechanical advantage of the inspiratory muscles in emphysematous hamsters would not preclude to reach a high TLC and thus a low RV/ TLC. Thus, it can be assumed that the RV/TLC ratio is truly low in emphysematous hamsters as compared to humans.

As with other studies $[10,16]$, it was found that $\mathrm{CW}$ was higher than $\mathrm{CL}_{\mathrm{L}}$ in control hamsters. As expected, the $\mathrm{CL} / \mathrm{CW}$ ratio decreased after induction of emphysema because of the increase in CL (median value in Sham group: 0.74). For obvious reasons, CWmax could not be measured. It is reasonable, however, to postulate that CWmax is directly related to $\mathrm{CW}$. Accordingly, the $\mathrm{CWmax} / \mathrm{CL}$ ratio should also be very low in emphysematous hamsters as compared to humans.

Considering that emphysematous hamsters have a low RV/TLC ratio and a high $\mathrm{CWmax} / \mathrm{CL}$ ratio, the model of Fessler and Permutt [5] predicts a lack of improvement in airflow obstruction after LVRS.

Another striking difference between emphysematous hamsters and humans relates to VC. An increase in

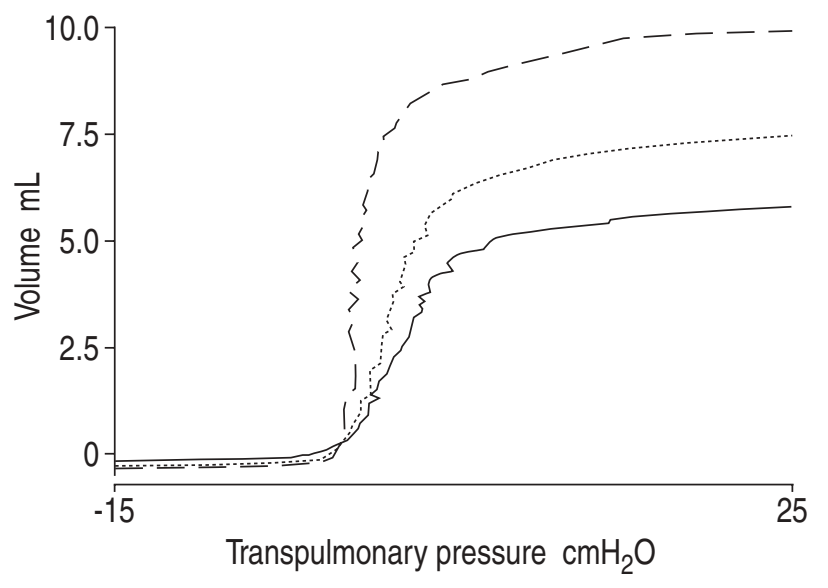

Fig. 4.-Quasistatic transpulmonary pressure $(P \mathrm{~L})$ /volume curves. Representative $P$ L/volume curves from animals of control $(-)$, Sham $(---)$ and lung volume reduction surgery $(\cdots \cdots \cdots \cdots)$ groups are depicted. For convenience, functional residual capacity was arbitrarily set at the point of 0 volume. Note that even at low positive transpulmonary pressure, lung volume is much higher in Sham than in the control group.
VC in Sham as compared to Ctrl and a significant decrease after LVRS was found. According to the model of Fessler and Permutt [5] and postulating an absence of airway tone (and, accordingly, a transpulmonary pressure of airway closure $(P \mathrm{TM})=0)$ :

$$
\mathrm{VC}=[(\mathrm{VWmax} 0-\mathrm{RV}) /(\mathrm{CWmax}+\mathrm{CL})] \times \mathrm{CL}_{\mathrm{L}}
$$

where VWmax0 is the volume at the point of intersection of the latter curve with the volume axis [5]. As discussed earlier, transposing this formula in this model is cautionary. However, if humans were to have a CWmax similar to $\mathrm{CL}$, and if VWmax0 was to increase in the same proportion as CWmax, then VC would be predicted to increase with emphysema. The picture would thus be quite similar to the one observed in the hamsters of the present study. Moreover, the model also predicts a decrease in VC after LVRS when the initial RV/TLC is relatively low and the CWmax is relatively high compared to CL. This fits very well with the decrease in VC observed in the present study.

The analysis of bronchial diameters on lung sections also showed striking differences as to the effects of emphysema in humans and hamsters. In humans, it has been shown that the distribution of the diameters of the peripheral airways is displaced towards smaller values in emphysematous lungs as compared to normal or senile lungs $[6,17]$. Using three-dimensional reconstruction of the septal system of human lungs, VERBEKEN et al. [18] were able to demonstrate that in addition to intrinsic inflammation and loss of elastic recoil, a competition for space between emphysematous zones and peripheral airways played a role in these findings and in airflow limitation. In the present study, the displacement of the distribution of peripheral airways diameters was also observed, but appeared to be much less pronounced than in humans. This can be seen when comparing figure 3 with figure 5 .

The authors believe that the high compliance of the chest wall in hamsters could explain these differences. As others have previously found $[10,16], \mathrm{CW}$ (data not

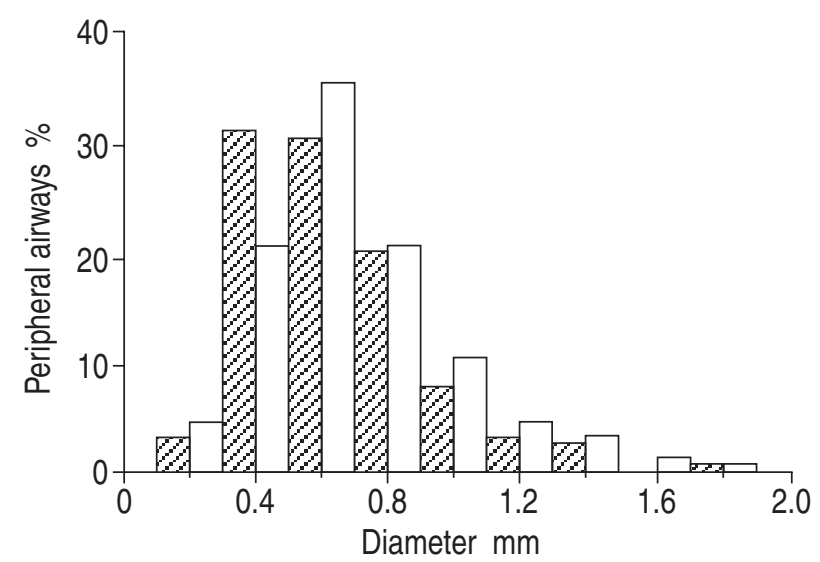

Fig. 5.-Mean frequency distribution of peripheral airways in normal and emphysematous humans. $\square$ : normal; $\mathbb{Z}$ : emphysematous humans. As can be seen from the comparison with figure 3 , the shift towards smaller diameters in emphysema is more important in humans than in hamsters. Adapted with permission from [6]. 
shown) was higher than $\mathrm{CL}_{\mathrm{L}}$ in hamsters. Hence, the competition for space is predicted to be absent when elastase-induced emphysema develops. The repartition of the airway diameters observed in figure 3 tends to confirm this prediction.

The model used in the present study has several potential limitations. First, respiratory mechanics demonstrate significant differences with humans. These differences probably explain the relatively limited reduction in indices of MEF in emphysematous hamsters. However, as discussed earlier, these differences allowed for the testing of the hypotheses, which would be difficult to do in humans since respiratory mechanics are difficult to manipulate in severe emphysema. Secondly, the elastase-induced emphysema is diffuse and very closely simulates human panlobular emphysema [19]. LVRS in panlobular emphysema associated with $\alpha_{1}$-antitrypsin deficiency has provided conflicting results in the long term [20, 21]. Nevertheless, short-term results are consistently favourable, suggesting that poor longterm results are due to accelerated loss of the effect after surgery. As emphysema was diffuse in the present study, lung resection was not targeted at selected involved lung zones. However, in line with short-term results of LVRS in patients with $\alpha_{1}$-antitrypsin deficiency, the model of Fessler and Permutt [5] still predicts a significant improvement in FEV1 in this situation, providing RV/TLC is high and CWmax/ $\mathrm{CL}$ is low.

To conclude, the application of lung volume reduction surgery in emphysematous animals with strikingly different respiratory mechanics as compared to humans, allowed for the demonstration that an increase in elastic lung recoil is not sufficient to improve airway function in emphysema. This indirectly supports the assumption that the mismatch between lung and chest-wall compliances is an important determinant of the expected improvement in airway function after lung volume reduction surgery in humans [5]. In the present study, it was hypothesized that the low slope of the pressure/volume curve of the chest wall under conditions of maximal inspiratory muscle activity/lung compliance ratio (and high residual volume/total lung capacity ratio) observed in humans compared to hamsters, actually promotes a competition for space within the thoracic cage when emphysema develops, thereby hampering airway function. These ratios are respectively much higher and much lower in emphysematous hamsters as is the competition for space. This was supported by the results of the airway morphometry study. The concepts derived from this study may have practical implications for the selection of patients for lungvolume reduction surgery. A high residual volume/ total lung capacity volume as well as a low slope of the pressure/volume curve of the chest wall under conditions of maximal inspiratory muscle activity/lung compliance ratio, should be considered as predictors of good response in terms of forced expiratory volume in one second. An alternative for the high residual volume/total lung capacity ratio could be a low, slow vital capacity. Prospective clinical studies testing these suggestions are warranted.

\section{References}

1. Geddes D, Davies M, Koyama H, et al. Effect of lung-volume-reduction surgery in patients with severe emphysema. N Engl J Med 2000; 343: 239245.

2. Criner GJ, Cordova FC, Furukawa S, et al. Prospective randomized trial comparing bilateral lung volume reduction surgery to pulmonary rehabilitation in severe chronic obstructive pulmonary disease. Am J Respir Crit Care Med 1999; 160: 2018-2027.

3. Pompeo E, Marino M, Nofroni I, Matteucci G, Mineo TC. Reduction pneumoplasty versus respiratory rehabilitation in severe emphysema: a randomized study. Pulmonary Emphysema Research Group. Ann Thorac Surg 2000; 70: 948-953.

4. Gelb AF, Zamel N, McKenna RJ Jr, Brenner M. Mechanism of short-term improvement in lung function after emphysema resection. Am J Respir Crit Care Med 1996; 154: 945-951.

5. Fessler HE, Permutt S. Lung volume reduction surgery and airflow limitation. Am J Respir Crit Care Med 1998; 157: 715-722.

6. Verbeken EK, Cauberghs M, Lauweryns JM, van de Woestijne KP. Anatomy of membranous bronchioles in normal, senile and emphysematous human lungs. J Appl Physiol 1994; 77: 1875-1884.

7. Marchand E, De Leyn P, Gayan-Ramirez G, et al. Lung volume reduction surgery does not improve diaphragmatic contractile properties or atrophy in hamsters with elastase-induced emphysema. $\mathrm{Am}$ J Respir Crit Care Med 2000; 162: 1052-1057.

8. Patra AL. Comparative anatomy of mammalian respiratory tracts: the nasopharyngeal region and the tracheobronchial region. J Toxicol Environ Health 1986; 17: 163-174.

9. Reid WD, Davies C, Pare PD, Pardy RL. An effective combination of anaesthetics for 6-h experimentation in the golden Syrian hamster. Lab Anim 1989; 23: 156162.

10. Koo KW, Leith DE, Sherter CB, Snider GL. Respiratory mechanics in normal hamsters. $J$ Appl Physiol 1976; 40: 936-942.

11. Palecek F, Palecekova M, Aviado DM. Emphysema in immature rats. Condition produced by tracheal constriction and papain. Arch Environ Health 1967; 15: 332-342.

12. Matsuba K, Thurlbeck WM. The number and dimensions of small airways in nonemphysematous lungs. Am Rev Respir Dis 1971; 104: 516-524.

13. McKenna RJ Jr, Brenner M, Fischel R, Gelb AF. Should lung volume reduction for emphysema be unilateral or bilateral? J Thorac Cardiovasc Surg 1996; 112: 1331-1339.

14. Keenan RJ, Landreneau RJ, Sciurba FC, et al. Unilateral thoracoscopic surgical approach for diffuse emphysema. J Thorac Cardiovasc Surg 1996; 111: 308316.

15. Sciurba FC, Rogers RM, Keenan RJ, et al. Improvement in pulmonary function and elastic recoil after lung-reduction surgery for diffuse emphysema. $N$ Engl J Med 1996; 334: 1095-1099.

16. Lai YL. Lung volume and pleural pressure in the anesthetized hamster. J Appl Physiol Environ Exercise Physiol 1979; 46: 927-931.

17. Petty TL, Silvers GW, Stanford RE. Small airway dimension and size distribution in human lungs with 
an increased closing capacity. Am Rev Respir Dis 1982; 125: 535-539.

18. Verbeken EK, Cauberghs $M$, van de Woestijne KP. Membranous bronchioles and connective tissue network of normal and emphysematous lungs. J Appl Physiol 1996; 81: 2468-2480.

19. Karlinsky JB, Snider GL. Animal models of emphysema. Am Rev Respir Dis 1978; 117: 1109-1133.
20. Gelb AF, McKenna RJ, Brenner M, Fischel R, Zamel N. Lung function after bilateral lower lobe lung volume reduction surgery for alpha1-antitrypsin emphysema. Eur Respir J 1999; 14: 928-933.

21. Cassina PC, Teschler H, Konietzko N, Theegarten D, Stamatis G. Two-year results after lung volume reduction surgery in alpha1-antitrypsin deficiency versus smoker's emphysema. Eur Respir J 1998; 12: 1028-1032. 